\title{
The use of digital models of hemodynamics for the development of the 21st century skills as a components of healthcare competence of the physical education teacher
}

\author{
Oksana Klochko ${ }^{1, *}$, Vasyl Fedorets ${ }^{2}$, Olena Maliar ${ }^{2}$, and Vitaliy Hnatuyk ${ }^{3}$ \\ ${ }^{1}$ Vinnytsia Mykhailo Kotsiubynskyi State Pedagogical University, Department of mathematics and informatics, Vinnytsia, 21001, \\ Ukraine \\ ${ }^{2}$ Vinnytsia Academy of Continuous Education, Department of psychological and pedagogical education and social sciences, Vinnytsia, \\ 21000, Ukraine \\ ${ }^{3}$ Berdyansk State Pedagogical University, Department of biology, health of a person and physical rehabilitation, Berdyansk, 71100 , \\ Ukraine
}

\begin{abstract}
The article explores the use of digital models of hemodynamics to improve the health-saving competence of Physical Education teachers in postgraduate education through the integrative development of critical thinking and digital skills. The digital skills and critical thinking of a Physical Education teacher are relevant components of the $21^{\text {st }}$ century skills system and are components of the health competence of a Physical Education teacher whose improvement is an important educational condition for the implementation of the sustainable development concept. The use of digital hemodynamic models, together with dialogical maieutics, reflexive and interactive educational practices, is an effective innovative educational technology that promotes the integrative development of digital skills, critical thinking, and the formation of fundamental and practically oriented morphology-based knowledge of cardiovascular system. Formed digital skills, critical thinking and knowledge of cardiovascular morphophysiology in Physical Education teacher is presented as a personal and intellectual condition for the prevention of sudden cardiac death of children and other cardiac pathology in the educational process during physical activity. The results of the study confirm the effectiveness of the use of digital models of hemodynamics to improve the healthsaving competence of Physical Education teachers in postgraduate education through the integrative development of critical thinking and digital skills.
\end{abstract}

\section{Introduction}

Today, the global issue of preserving civilization and the Earth is building sustainable systems for securing a sustainable future. The focus of their formation is also the development of $21^{\text {st }}$ century skills [1]. "The Sustainable Development Report 2019" identifies six SDG (Sustainable Development Goals) transformations that are necessary to ensure sustainable development [2]: Education, Gender, and Inequality; Health, Well-being, and Demography; Energy Decarbonization and Sustainable Industry; Sustainable Food, Land, Water and Oceans; Sustainable Cities and Communities; Harnessing the Digital Revolution for Sustainable Development.

The transformations highlighted by the researchers J. Sachs, [2] for the purpose of SDG operationalization are indicated [2]. They are necessary for the development of technologies, attracting effective investments, ensuring optimal management, coherence of political decisions, maintaining equality of all segments of the population. Transformations are closely related and interdependent. In particular, improving education contributes to the achievement of sustainable development goals in health, the environment and reducing inequalities [2].

Human health within the modern paradigm of sustainable development, the actual component of which is optimal motor activity, is considered as an anthropological phenomenon congruent with the conservation of the Earth and contributing to the achievement of the goals of sustainable development. A significant person who can effectively and professionally implement these requests for physical activity and preserve the health of children is a Physical Education teacher and trainer. Improving the health-saving competence of a Physical Education teacher [3] in postgraduate education is based on the idea of developing a critical thinking of a teacher and digital skills that are relevant components of "the $21^{\text {st }}$ century skills system".

The concept of critical thinking is formed by J. Dewey on the basis of the cognitive and practical significance of life practices and experiences, humanistic intentions and the idea of respect for the individual [4]. The philosopher defined it as "reflective thinking", the

* Corresponding author: klochkoob@gmail.com 
ultimate intellectual goal of education, individual and social value [4]. As E. Ivunina points out, critical thinking is characterized by: systematic, consistent, multi-perspective, metacognitive, reflexive, multi-level, argumentative, non-dogmatic, logical [5]. According to A. Koroleva a significant aspect of the critical thinking of the roots of which are in antiquity is the dialogicalmothic context of its formation and realization, as well as the fact that it is the mental basis of socio-critical pedagogy [6]. Critical thinking according to J. Dewey contributes to “... reducing social evil." [7, p. 4; 8, p. 10]. A valuable aspect of critical thinking is that it is aimed at developing democracy $[8$, p. 10-11; 9].

V. Osadchyi explored the development of digital skills through the use of Internet resources, educational content management systems, social services, mobile technologies, artificial intelligence technologies, cloud technologies [10]. V. Bykov [11] emphasizes the enhancement of computer training at all levels of education, the careful use of digital educational resources and software, with the obligatory involvement of scientists and teachers in their creation. V. Bykov and M. Leshchenko revealed the theoretical and methodological foundations of the formation of digital humanistic pedagogy with the convergence of physical and virtual learning spaces [12]. O. Klochko, V. Nagayev, V. Klochko, explored ways to implement a person-centered paradigm using an empowerment approach to ensure sustainable personal development in the use of computer-oriented systems to shape the digital skills of future managers [13]. As part of O. Klochko i V. Fedorets health-saving approach, we have developed models for detecting signs of digital-related violations and predicting the risks of Internet addiction [14].

This study uses the methodological potential of the development of S. Semerikov and I. Teplitskyi dedicated to the application of ideas of fundamentalization [15]. Researchers draw attention to the need to: "preserve the core of content, which by its very nature must be conservative; learning basic competencies" [15, p. 251]. Effective methodological avenues for fundamentalization are the integrative use of hemodynamic models, digital skills and critical thinking.

From the point of view of P. Anokhin's teaching [16] on functional systems, health-saving competence of Physical Education teacher, as well as critical thinking, which we consider as a significant aspect of it, are specific "personality-mental" formations (functional systems) adapted to a certain type of activity. Specifying, we note that the health-saving competence of Physical Education teachers, critical thinking and information skills, besides universal general dimension and possibilities of application, have specific use, which is aimed at solving a relatively limited range of professional problems.

Such central problems are the vital and socially significant issues of preserving the life and cardiological health of children in the educational process. Accordingly, these problems determine the need for the Physical Education teacher to acquire knowledge of the phenomenology of the cardiovascular system and the ability to think critically in order to preserve the life and health of children. In these problems the disclosure of the phenomenology of the cardiovascular system is central and determining knowledge of hemodynamics (blood movement science) $[17 ; 18 ; 19 ; 20]$ and their ability to use in professional activity. This is due to the fact that hemodynamic disorders that can occur as a result of motor activity or under the influence of other factors underlie the development of acute cardiac pathology and, above all, sudden cardiac death [21], which is an urgent problem of youth sports in all countries of the world. Really existing life and learning situations and physical exercises and motor actions can contribute to the formation of hemodynamic disorders and pose a risk to the cardiac health of the child. Therefore, in order to reduce the risks to the health and life of the child Physical Education teacher, it is necessary to develop appropriate intellectual tools, the significant components of which are critical thinking [4; $5 ; 6 ; 7 ; 8 ; 9]$ and digital skills $[10 ; 11 ; 12 ; 13 ; 14]$. Critical thinking and digital skills are necessary for understanding and life-oriented interpretation of pedagogical situations, training regimes, motor actions, exercises, techniques, technologies and motor phenomenology of the child based on the use of knowledge of hemodynamic phenomena and their ability to apply them in professional sphere. To develop hemodynamics knowledge at the level necessary for practically oriented understanding of hemodynamic risks by the Physical Education teacher in relation to the development of their health skills, we interpret the critical thinking using actual digital thinking, including first and digital hemodynamic models.

In research, the problem of using digital models of hemodynamics to develop critical thinking and digital skills as components of the health-care competency of a Physical Education teacher in postgraduate settings has not been sufficiently addressed. Thus, this problem is relevant in the context of the development of $21^{\text {st }}$ century skills to secure a sustainable future.

The aim of the study. Improving the health-care competency of a Physical Education teacher in postgraduate education through the integrative development of critical thinking and digital skills based on the use of digital hemodynamic models.

\section{Methods of the research}

The methods and approaches used in the study are: analysis, synthesis; statistical in particular regression analysis; questionnaire; competent [22], health-saving, ontological, medical hygienic, pathophysiological, pathopedagogical, hemodynamic, transdisciplinary, systemic, holistic, humanistic, preventive, psychological, anthropological, cultural, hermeneutic, axiological, epistemological, innovative, problematic.

We have used the methodological, epistemological and axiological potential of the concepts: knowledge transfer, sustainable development, "Care of the Earth" (A. Gore) [23], sociocultural "construction" of health and pathology (M. Foucault) [24]. 
We applied an intellectually oriented technique. The purpose of this technique was the integrative development of critical thinking and its digital skills of Physical Education teacher, as well as the formation of knowledge of hemodynamics. Diagnosis of the results of the study was conducted using the questionnaire presented below. The questioning procedure consisted in asking students to use digital hemodynamic models to answer questions.

In this questionnaire, the correct answer for all questions is "No". In addition to assessing the formation of critical thinking, this questionnaire aims to determine the level of knowledge of hemodynamics.

Questionnaire of Fedorets-Klochko to assess the formation of critical thinking of a Physical Education teacher (trainer) based on the interpretation of hemodynamic knowledge:

1) From the standpoint of knowledge of hemodynamics, the presence of protective movements and a sharp decrease in the student's desire to actively participate in Physical Education indicates the normative state of his cardiovascular system and the presence of laziness, passivity and unwillingness to exercise. ("Yes","No").

2) From the standpoint of hemodynamic knowledge, the presence of a significant desire of the student to sit after or during physical activity indicates that he or she is neglected to exercise and lacks willpower. ("Yes","No").

3) Significant and rapid increase in blood in a large circle, including depot (spleen and liver) due to physical activity indicates good heart training and a good level of physical fitness, which indicates the need to increase the intensity of training. ("Yes", "No").

4) Significant and rapid increase in blood volume in the large circulatory cycle against the backdrop of reducing it in the small circle resulting from exercise results in better provision of tissues with oxygen and nutrients, which in turn is a physiological condition for the need to increase the intensity of training. ("Yes","No").

5) The accumulation of blood in the depot, spleen and liver during physical activity is caused only by the pumping function of the left ventricle of the heart. ("Yes","No").

6) The opening and expansion of many vessels of the microcirculatory bed (capillaries, precapillaries, arterioles, venules, etc.) will only lead to positive results in improving local circulation. ("Yes","No").

7) The accumulation of blood in the depot in the liver and spleen during sleep is due to increased work of the left ventricle. ("Yes", No").

8) Increased work of the left ventricle directly promotes active inflow ("pushing") of blood to the right atrium. ("Yes","No").

\section{Results and discussion}

In the context of implementing sustainable development strategies, we consider the Sustainable Development Goals (SDGs), which are most correlated with the studied components of the development of the health- saving competence of a Physical Education teacher [1]: 1) Transformation No 1. Education, Gender, and Inequality. Involving ministries of Education This transformation covers education investment, social protection, regulation of labor legislation and research. 2) Transformation No 2. Health, Well-being, and Demography. The transformation involves group interventions to provide Universal Health Coverage (UHC). Promoting a healthy lifestyle and ensuring social key factors for health and well-being are important. 3) Transformation No 6. Harnessing the Digital Revolution for Sustainable Development. This transformation is one of the keys to ensuring that all the goals of a sustainable future are met. Accordingly, if properly used, it contributes to the sustainable development and implementation of these goals.

The physical competence of a Physical Education teacher is a holistic "intellectual-personal-activity" phenomenon formed by the integration of many components [3]. Against this background, and considering the recommendations of the World Economic Forum on $21^{\text {st }}$ century skills, we consider in the study only some of the components of the Physical Education teacher's competency, namely, Critical Thinking and Digital Skills $[25 ; 26 ; 27 ; 28]$ Critical Thinking and Digital Skills are one of the $21^{\text {st }}$ century skills that are important for (implementing the concept of sustainable development) of securing a sustainable future.

So, we consider the factors influencing the SDG index [1] (Table 1): Ensure healthy lives and promote well-being for all at all ages (GOAL 3, Good health and well-being); Ensure inclusive and equitable quality education and promote lifelong learning opportunities for all (GOAL 4, Quality education), that includes the factors information and communications technology (ICT) skills. By region of study SDG Ukraine is classified as Eastern Europe and Central Asia. Therefore, we will look at the Good Health and Well-Being and Quality Education indices of the 23 countries in the region (except for 4 countries for which there are no SDG data). According to the Sustainable Development Report 2019 [1], the average SDG for Eastern Europe and Central Asia is 70,4, Good health and well-being 77,11 , Quality education $-89,2$.

In order to perform regression analysis on the basis of the experimental data in Table 1, we build a mathematical model (1) that describes the behavior of the SDGs depending on the change in the factors Good health and well-being, Quality education that affect it:

$$
y=f\left(x_{1}, x_{2}\right)+\varepsilon,
$$

where $y$ is the dependent variable SDG (response, regressor); $x_{1}, x_{2}$ are independent variables (regressors, predictors) respectively Good health and well-being, Quality education; $\varepsilon$ is a random error.

The purpose of the regression model is to investigate the impact of Good health and well-being, Quality education on the SDGs in Eastern Europe and Central Asia, to which Ukraine also belongs. 
We construct a two-factor linear regression model $y=F(x)$ :

$$
y=b_{0}+b_{1} x_{1}+b_{2} x_{2}
$$

Table 1. SDGs and its Impact Factors: Good health and well-being, Quality education, 2019 y. [1].

\begin{tabular}{|c|l|c|c|c|}
\hline \multirow{2}{*}{ No } & \multicolumn{1}{|c|}{ Country } & $\begin{array}{c}\text { Global } \\
\text { Index } \\
\text { Score, } \boldsymbol{y}\end{array}$ & $\begin{array}{c}\text { Good } \\
\text { health } \\
\text { and well- } \\
\text { being, } \boldsymbol{x}_{\mathbf{1}}\end{array}$ & $\begin{array}{c}\text { Quality } \\
\text { education, } \\
\boldsymbol{x}_{\mathbf{2}}\end{array}$ \\
\cline { 3 - 5 } & $\mathbf{( 0 - 1 0 0 )}$ & $\mathbf{( 0 - 1 0 0 )}$ & $\mathbf{( 0 - 1 0 0 )}$ \\
\hline 1 & Afghanistan & 49,65 & 38,71 & 23,67 \\
\hline 2 & Albania & 70,27 & 82,21 & 93,40 \\
\hline 4 & Armenia & 68,77 & 78,52 & 89,75 \\
\hline 5 & Azerbaijan & 70,46 & 75,29 & 90,76 \\
\hline 6 & Bosnia and Herzegovina & 69,39 & 80,26 & 99,38 \\
\hline 7 & Belarus & 77,44 & 81,73 & 96,79 \\
\hline 8 & Cyprus & 70,14 & 92,83 & 97,02 \\
\hline 9 & Georgia & 68,91 & 73,21 & 98,33 \\
\hline 10 & Croatia & 77,79 & 87,09 & 87,36 \\
\hline 11 & Kazakhstan & 68,71 & 75,77 & 90,98 \\
\hline 12 & Kyrgyz Republic & 71,62 & 70,08 & 91,07 \\
\hline 13 & Moldova & 74,41 & 74,82 & 82,66 \\
\hline 14 & North Macedonia & 69,38 & 80,00 & 88,32 \\
\hline 15 & Malta & 76,11 & 92,69 & 97,49 \\
\hline 16 & Montenegro & 67,25 & 79,88 & 96,27 \\
\hline 17 & Romania & 72,73 & 80,63 & 84,17 \\
\hline 18 & Russian Federation & 70,94 & 78,06 & 97,21 \\
\hline 19 & Serbia & 72,49 & 84,16 & 94,29 \\
\hline 20 & Tajikistan & 69,23 & 70,15 & 95,96 \\
\hline 21 & Turkmenistan & 64,26 & 67,77 & 99,64 \\
\hline 22 & Ukraine & 72,81 & 71,76 & 92,55 \\
\hline 23 & Uzbekistan & 71,13 & 77,62 & 93,62 \\
\hline
\end{tabular}

The matrix form of the equation (2):

$$
Y=B X \text {, }
$$

where

$$
Y=\left(\begin{array}{l}
y_{1} \\
y_{2} \\
\ldots \\
y_{23}
\end{array}\right), X=\left(\begin{array}{ccc}
1 & x_{11} & x_{21} \\
1 & x_{21} & x_{22} \\
\ldots & \ldots & \ldots \\
1 & x_{231} & x_{232}
\end{array}\right), B=\left(\begin{array}{l}
b_{1} \\
b_{2} \\
b_{3}
\end{array}\right) .
$$

The coefficients $b_{1}, b_{2}, b_{3}$ of the regression model (2) are found by the formula [29, p. 87]:

$$
B=\left(X^{\mathrm{T}} X\right)^{-1} X^{\mathrm{T}} Y,
$$

where $X^{\mathrm{T}}$ is the matrix, transposed to the matrix $X$; $\left(X^{\mathrm{T}} X\right)^{-1}$ is the inverse of the matrix $\left(X^{\mathrm{T}} X\right)$.

As a result of the calculations, a regression model is constructed:

$$
y=37,0+60,38 x_{1}+0,04 x_{2} .
$$

The calculated coefficient of determination $R^{2}=0,67$. This value is medium, closer to high. Estimated value of Fisher-Snedecor $F$-test $F=20,39$ [29]. Tabular value $F_{0,5 ; 2 ; 20}=3,49 . \quad F>F_{0,5 ; 2 ; 20}$. According to the FisherSnedecor $F$-test, the regression equation is significant. Given the value of the coefficient of determination and the Fisher-Snedecor $F$-test, we consider this equation (6) to be usable.
Physical activity is a key contributor to almost all Sustainable Development Goals. Appropriate measures and attracted investment to increase physical activity should be a priority for each country. In addition to promoting the health and well-being of people of all ages, they aim to address other priorities of achieving the Sustainable Development Goals. Regular physical activity contributes to the prevention and treatment of noncommunicable diseases, reduces the level of their risk factors, promotes the health of the population throughout life. Table 2 shows the benefits of implementing strategies to increase physical activity that can help achieve [30].

The need to improve the digital skills of Physical Education teachers in postgraduate education is due to the fact that they are a component of the professional competence of the teacher, refer to the skills of the $21^{\text {st }}$ century [1] and are integral to the goals of sustainable development.

The digital competences of Physical Education teachers in terms of postgraduate education are components of which digital skills are characterized by systematic, holistic, integrative nature. Their main components are the ability to: navigate the information space; perform actions with data in a professional activity; use common and application software. The development of digital skills of a Physical Education teacher is based on a competent approach [22]. The development of personality culture, as well as the use of the humanistic potential of ideas of multiculturalism, tolerance, Europeanization, safety and high quality of life. In the context of pedagogical integration [31], we emphasize the need to improve digital skills in combination with critical thinking.

The term "critical thinking" was first used by the classic American pragmatist J. Dewey in "How We Think" [4] in 1910. The philosopher draws attention to the reflexive [4; 8, p. 9], problematizing [8, p. 11;9], active, practical, humanizing [1], the life-giving character of critical thinking. Important for the unfolding of the phenomenology of health is the eudemonic aspect of critical thinking aimed at achieving individual happiness [7, p. 4; 8, p. 10] and life success. J. Dewey's merit is also that he sees critical thinking not only as a mental tool, but as an actual educational strategy and purpose [9]. For the development of the health-saving competence of a Physical Education teacher, the development of critical thinking is relevant because it has a mental setting for identifying [5] and understanding inconsistencies. That is, critical thinking contributes to the objectification, evidence, reasoning, logic that is necessary for a health-oriented understanding of the phenomenon of the person and his health. Critical thinking is the basis of a specific mental "tool" of a physical education teacher.

Critical thinking is directed at the formation of objectified and realistic understandings, interpretations and visions by the Physical Education teacher of the child and his or her health. Critical thinking as analytical, synthetic, practically oriented in its mental nature, is accordingly close to the digital skills that are represented as cognitive matrices formed on the basis of 
certain algorithms. This defines the educational logic of its integrated formation.

Table 2. Co-benefits of policy action to increase physical activity [30].

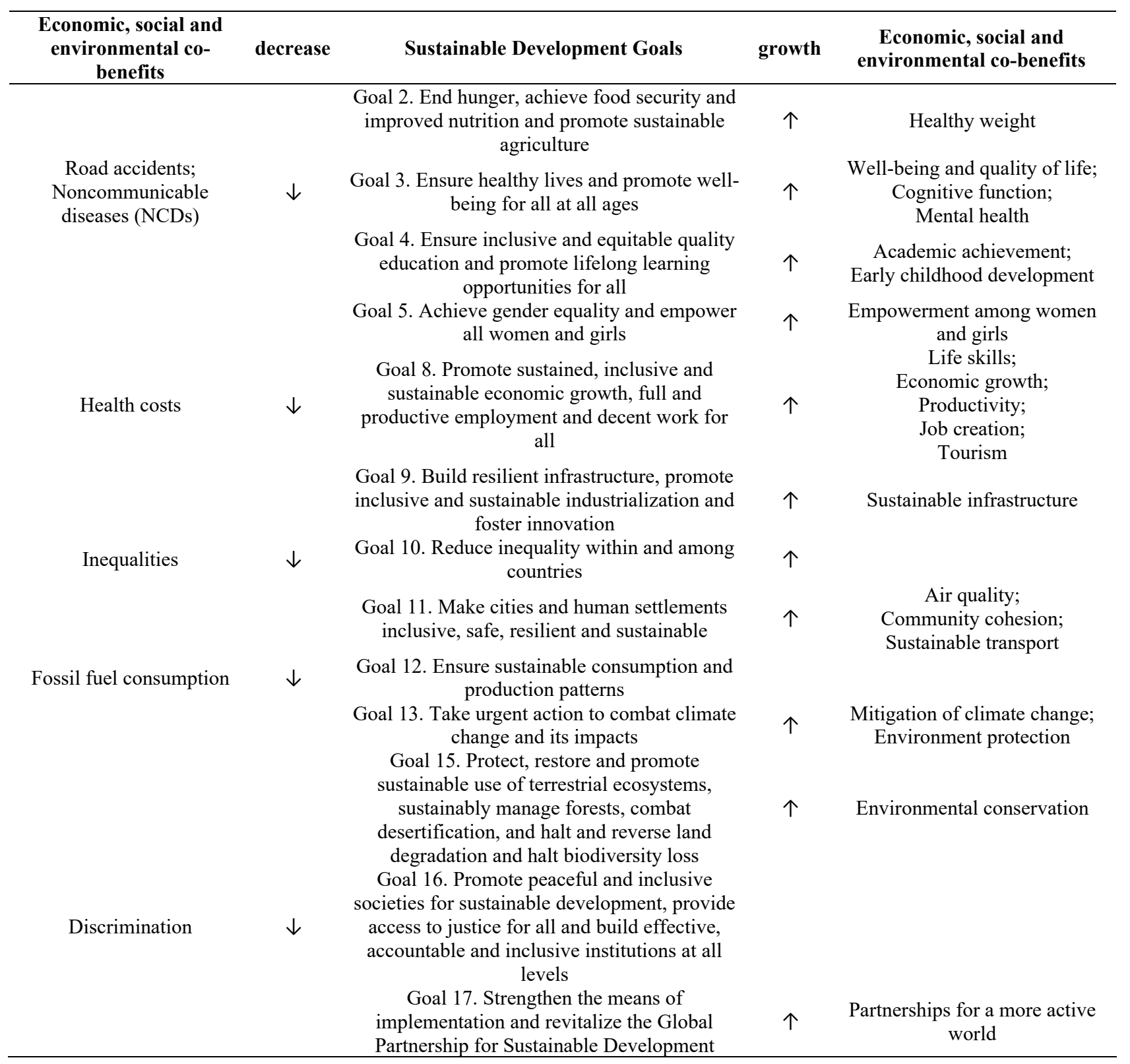

Accordingly, critical thinking $[4 ; 5 ; 6 ; 7 ; 8 ; 9]$ is decisive and system-organizing in the professional activity of a Physical Education teacher aimed at maintaining health. It is also significant for its social and professional adaptation and self-realization.

An important methodological aspect of this issue is the need to improve the critical thinking of the teacher by studying normative and pathological anthropological phenomena in particular on the basis of digital hemodynamic models $[32 ; 33]$.

The urgency of the use of digital hemodynamic models is determined by the professional need to form a practically oriented knowledge and understanding of the functioning of the cardiovascular system in the teacher of Physical Education, interdependent with regard to the specific motive activity and features of biomechanics. In addition, it is important for the teacher to understand the health and risk situations of children who are experiencing physical activity in physical education classes. Therefore, the Physical Education teacher must have critical thinking to deal with such problems effectively. A structural and defining aspect is that critical thinking is seen as a relevant component of health-saving thinking.

It is important to take into account that hemodynamic disorders can occur during motor activity sharply, that is relatively quickly and without prior signs or manifestations, which requires immediate and optimal decisions. It should also be born in mind that these hemodynamic phenomena tend to have rapid and rather unpredictable dynamics. Thus, critical thinking is an actual intellectual tool for decision making.

In order to improve the critical thinking of the Physical Education teacher, as well as to correlate the formation of practically oriented knowledge of the physiology of the cardiovascular system, we used digital 
hemodynamic models of our own development and features: CVSS (Cardio-Vascular Simulation System) [19], BioUML [32], Sorin C5 System [33] and other (Figure 1, Figure 2).

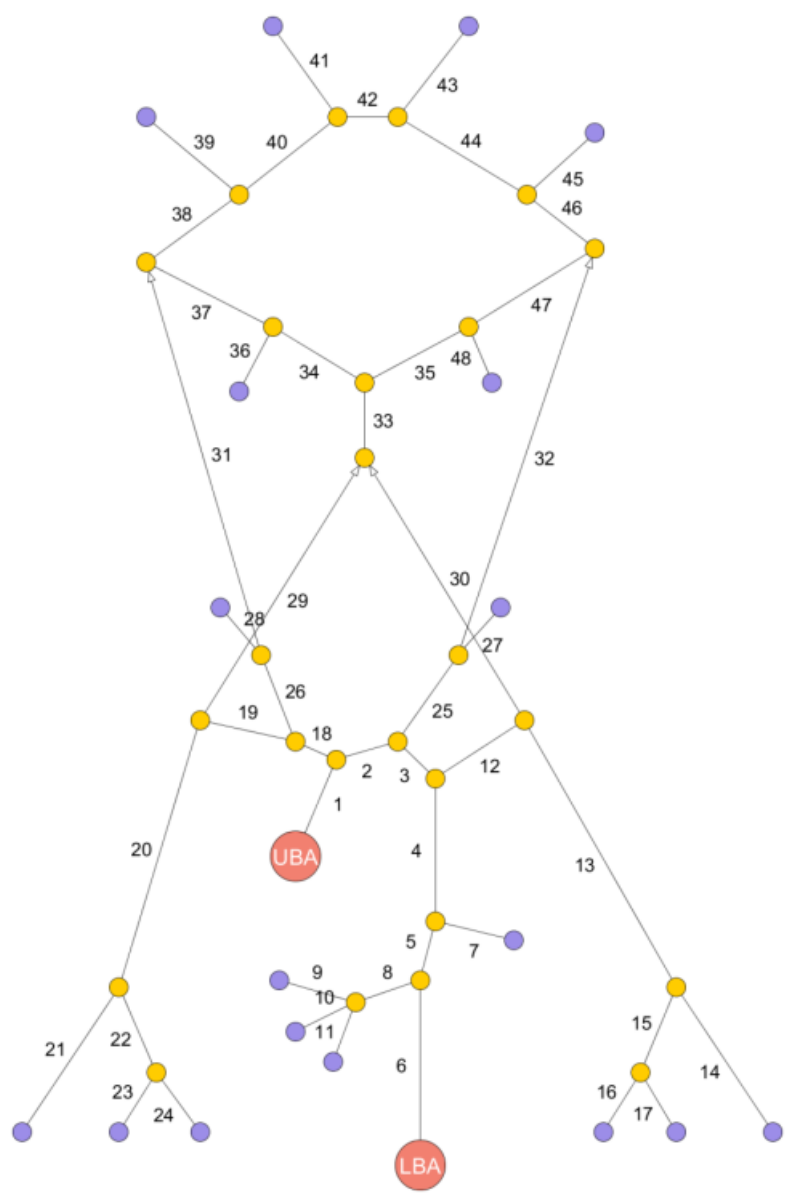

Fig. 1. One-scale model of hemodynamics for modeling the basilar artery [19].

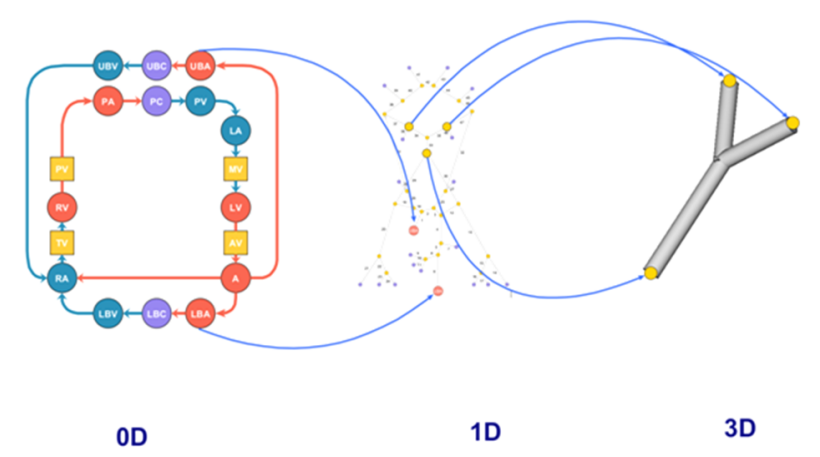

Fig. 2. Multiscale hemodynamics model for basilar artery modelling [19].

In addition to the use of digital hemodynamic models, the development of critical thinking has been utilized by auto-dialogic, reflexive and interactive practices, solving pedagogical problems, as well as analyzing specific real-life problems, questions, phenomena and experiences.

The study was made in 2017-2018. During the training courses for Physical Education teachers' positive dynamics of the development of critical thinking have been identified. The study involved 157 Physical Education teachers. The study was conducted at: Drohobych Ivan Franko State Pedagogical University, Chernihiv Regional Institute of Postgraduate Education Ushynsky, Sumy Regional Postgraduate Pedagogical Education Institute, and Mykolaiv Regional Postgraduate Education Institute. To determine the dynamics of the formation of critical thinking and knowledge of hemodynamics, we used "Questionnaire FedoretsKlochko assessment of the formation of critical thinking Physical Education teacher (trainer) based on the interpretation of knowledge of hemodynamics" (described above in research methods).

In the control group, which consisted of 75 people, hemodynamics studied without the use of digital hemodynamic models, the results are presented in Figure 3. The experimental group consisted of 82 people; the results are presented in Figure 4. The study of hemodynamics in this group was conducted both through the use of digital hemodynamic models and applying the techniques used in the control group.

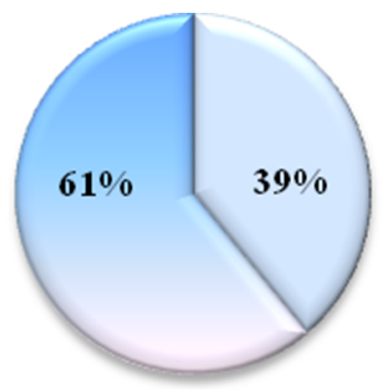

Fig. 3. Results of the questionnaire aimed at assessing the formation of critical thinking and knowledge of hemodynamics of Physical Education teachers, who studied without the use of digital hemodynamic models (control group).

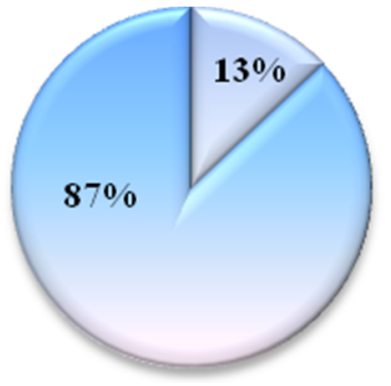

Fig. 4. Results of the questionnaire aimed at assessing the formation of critical thinking and knowledge of hemodynamics of Physical Education teachers, who have used digital hemodynamic models in training (experimental group).

As a result of the questionnaire aimed at assessing the formation of critical thinking and knowledge of hemodynamics of Physical Education teachers, the following results were obtained: teachers who studied without the use of digital hemodynamic models the number of correct answers is $61 \%$; teachers who have used digital hemodynamic models in training have correct answers of $87 \%$. So, the difference in correct answers between the two groups is $26 \%$. As can be seen from Figure 3 and Figure 4, improving critical thinking and developing knowledge of the hemodynamics of 
Physical Education teachers in postgraduate education has a positive dynamic, which is formed by the use of hemodynamic models.

The positive dynamics of the results are explained by the following factors: teachers' motivation to familiarize themselves with the indicated direction in connection with the need for knowledge of hemodynamic mechanisms of cardiac pathologies occurrence; the need to prevent sudden cardiac death; application of digital hemodynamic models in the educational process; using known knowledge in practically oriented interpretations and formats.

\section{Conclusion}

A significant cultural and educational condition for the implementation of the Sustainable Development Goals is health preservation and physical activity. This determines the need to improve the health-care competency of a Physical Education teacher and his professionalism, based on the values and goals of sustainable development, as well as through the transfer of health and information knowledge.

Based on the analysis of the coefficient $b_{1}=0,38$ equation (6) we can conclude that the relationship between the variables $y$ and $x_{1}$ (SDG and Good health and well-being)) is direct. As the value of the variable $x_{1}$ per unit increases, the value of the variable $y$ will increase by 0,38 (that is, with the increase in the unit Good health and well-being, the SDG will increase by $0,38)$. The impact of Quality education on the modelbuilt SDG is less. $b_{2}=0,04$ (equation (6), the relationship between the variables $\mathrm{y}$ and $x_{2}$ (SDG and Quality education SDG) is straightforward. With the increase in the value of the variable $x_{2}$ per unit, the value of the variable $y$ will increase by 0,04 (that is, with increasing Quality education per unit, SDG will increase by 0,04 ).

One of the reasons for this result may be that in the current context, the life cycle of professions is shortening. Currently, the field of education remains conservative, with some programs unchanged for many years. Therefore, the right set of skills is relevant, which in the future will help change the profession and retrain, as well as professionally and personally improve and be socially adapted. The future is variable and may evolve in different scenarios. Therefore, we identify skills that are designed for variant scenarios of the future and can help adapt to such changes.

At present, the development and improvement of $21^{\text {st }}$ century skills, namely critical thinking and digital skills, is relevant to ensure the achievement of sustainable development goals. In the process of improving the health-saving competence of a Physical Education teacher (trainer), an integral and interdependent skill development of the teacher is the integrative and interdependent development of critical thinking and digital skills based on the study of hemodynamics through the use of digital hemodynamic models. The development of critical thinking, digital skills and the formation of hemodynamic knowledge are aimed primarily at solving the current problem of modern education for the prevention of sudden cardiac death and other cardiac pathology in the educational process.

Digital hemodynamic models are intellectual learning systems that have significant educational, practical, epistemological, methodological, heuristic and axiological potentials. The methodological value of digital hemodynamic models is that they are ontologically, visually, holistically, as well as problematically and procedurally oriented, reveal the phenomenology of the cardiovascular system.

\section{References}

1. T. Wagner, The global achievement gap: Why even our best schools don't teach the new survival skills our children need-and what we can do about it (Hachette, 2014)

2. J. Sachs, G. Schmidt-Traub, C. Kroll, G. Lafortune, G. Fuller, Sustainable Development Report 2019 (Bertelsmann Stiftung and SDSN, New York, 2019)

3. V. Fedorets, Conceptualization of the anthropological model of the health preserving competence of a physical education teacher. Newslet. of the Grad. 5, 137-178 (2017)

4. J. Dewey, How we think (DC Heath \& Co Publishers, Chicago, 1910)

5. E.E. Ivunina, On various approaches to the concept of “critical thinking”. Y. Sc. 11, 170-174 (2009)

6. A.V. Koroleva, Philosophical aspects of critical thinking. Gaudeamus 1(17) (2011)

7. J. Dewey, Psychology and pedagogy of thinking (How we think) (Labirint, Moscow, 1999)

8. A.V. Zaitsev, "Critical Thinking" in John Dewey's Philosophical Reflection. Dialog 1(13) (2019)

9. D. Hitchcock, Supplement to critical thinking: History (SEP, 2018), https://plato.stanford.edu/ entries/critical-thinking/history.html. Accessed 5 Feb 2020

10. V. Osadchyi, Modern information and communication technologies for the professional training of future teachers. Edu.: Modern Discours. 2, 171-177 (2019). doi:10.32405/2617-3107-2019-120

11. V.Yu. Bykov, Digital transformation of society and development of computer and educational platform of education and science of Ukraine, Materials of the methodological seminar NAPN of Ukraine, (NAPS of Ukraine, Kyiv, 20-26, 2019)

12. V.Yu. Bykov, M.P. Leshchenko, Digital humanistic pedagogy: relevant problems of scientific research in the field of using ICT in education. Inf. Tech. and Learn. Tools 53(3), 1-17 (2016). doi:10.33407/itlt.v53i3.1417

13. O. Klochko, V. Nagayev, V. Klochko, M. Pradivliannyi, L. Didukh, Computer oriented systems as a means of empowerment approach implementation to training managers in the 
economic sphere. Inf. Tech. and Learn. Tools 68, 37-44 (2018). doi:10.33407/itlt.v68i6.2484

14. O.V. Klochko, V.M. Fedorets, An empirical comparison of machine learning clustering methods in the study of Internet addiction among students majoring in Computer Sciences. CEUR Workshop Proceedings 2546, 58-75(2019). http://ceurws.org/Vol-2546/paper03.pdf. Accessed 15 Feb 2020

15. S.O. Semerikov, I.O. Teplitsky, Teplytskyi Fundamentalizatsiia yak osnova rozvytku innovatsiinoi vyshchoi osvity (Fundamentalisation as a basis for the development of innovative higher education). Collection of Sci. Papers of KPNU: Ped. Ser. 15, 249-251 (2009)

16. P.K. Anokhin, Cybernetics of Functional Systems (Medicine, Moscow, 1998)

17. M.V. Abakumov, V.B. Koshelev, S.I. Mukhin at al., A software package for modeling hemodynamics on a spatial graph of the cardiovascular system. Physiol. of blood circulat. 15 (2012)

18. S.V. Frolov, S.V. Sindeev, V.A. Lishchuk, D.Sh. Gazizova, S.A. Medvedev, A four-chamber model of the human cardiovascular system. Questions of modern Sc. and Pract. 2, 51-60 (2012)

19. S.V. Frolov, S.V. Sindeev, V.A. Lischouk, D.S. Gazizova, D. Liepsch, A. Balasso, Development of multiscale hemodynamics model for research of basilar artery circulation. Problems of Contemporary Sc. and Pract. Vernadsky University 48(4), 46-53 (2013)

20. A.Ya. Bunicheva, S.I. Mukhin, N.V. Sosnin, A.B. Khrulenko, Mathematical modeling of quasione-dimensional hemodynamics. J. of Comput. Math. and Math. Phys. 55(8), 1417-1428 (2015)

21. J. Higgins, A. Andino, Soccer and Sudden Cardiac Death in Young Competitive Athletes: A Review. J. of Sports Med. (2013). doi:10.1155/2013/967183

22. D. Raven, O.N. Yarygin, A.A. Korostelev, Competentology: from praxeology to sociocybernetics. Azimuth of Sc. Res.: Ped. and Psych. 6(1(18)), 167-175 (2017)

23. A. Gore, Earth in the Balance: Ecology and the Human Spirit. J. of Leisure Res., 25(2), 218 (1993)

24. M. Foucault, Birth of the clinic (Smysl, Moscow, 1998)

25. Jobs Of Tomorrow: Mapping Opportunity in the New Economy (WEF, Cologny/Geneva Switzerland, 2020),

http://www3.weforum.org/docs/WEF_Jobs_of_Tom orrow_2020.pdf. Accessed 5 Feb 2020

26. The Future of Jobs Report 2018 (WEF, Cologny/Geneva Switzerland, 2018), http://www3.weforum.org/docs/WEF_Future_of_Jo bs_2018.pdf. Accessed 5 Feb 2020

27. The Future of Jobs Employment: Skills and Workforce Strategy for the Fourth Industrial Revolution (WEF, Cologny/Geneva Switzerland,
2016),

http://www3.weforum.org/docs/WEF_Future_of_Jo bs.pdf. Accessed 5 Feb 2020

28. New Vision for Education: Unlocking the Potentual of Technology (WEF, Cologny/Geneva Switzerland, 2015),

http://www3.weforum.org/docs/WEFUSA_NewVisi onforEducation_Report2015.pdf. Accessed 5 Feb 2020

29. N.S. Kremer, B.A. Putko, Ekonometrika (UnityDana, Moscow, 2002)

30. ACTIVE: a technical package for increasing Phys. Activ. (World Health Organization, Geneva, 2018), https://apps.who.int/iris/bitstream/handle/10665/275 415/9789241514804-

eng.pdf?sequence $=1$ \&isAllowed $=\mathrm{y}$. Accessed $5 \mathrm{Feb}$ 2020

31. N.K. Chapaev, Dissertation, Ural State Prof. Ped. Univ., 1998

32. BioUML: open platform for biomedical research. http://wiki.biouml.org/index.php/Landing. Accessed 15 Feb 2020

33. Stockert S5/Sorin C5 System. https://medicaldevices.icij.org/devices/usacardiovascular-devices-stockert-s5-sorin-c5-systembcda0969. Accessed 15 Feb 2020 